\title{
EL OFICIO DE DIFUNTOS EN LA EDAD MEDIA. LA LITURGIA FUNERARIA EN DOS CÓDICES MONÁSTICOS DEL ARCHIVO GENERAL DE NAVARRA
}

\author{
POR \\ JULIA BALDó ALCOZ \\ Universidad de Navarra \\ juliabaldoalcoz@gma \\ $\mathrm{Y}$ \\ JuLIA PAVÓn BENITO \\ Universidad de Navarra \\ jpavon@unav.es
}

\begin{abstract}
RESUMEN
Uno de los aspectos de la historia e historiografía de la muerte que menos eco ha tenido en este ámbito de investigación es la liturgia funeraria durante la Edad Media. Por ello, este artículo propone el estudio de la estructura y composición del modelo canónico del Oficio de difuntos, a partir de dos códices de procedencia navarra, con el objeto de comprender la cobertura eclesiástica desplegada durante y después de los funerales. De esta forma, podremos acercarnos a la parte canónica del ritual de acompañamiento a los muertos, en la que la comunidad cristiana de los vivos evocaba, a través de las oraciones, el más importante de sus dogmas: la esperanza de la resurrección.
\end{abstract}

PALABRAS CLAVE: Muerte, Edad Media, Liturgia funeraria, Oficio de difuntos, Oraciones.

\section{THE OFFICE OF THE DEAD IN THE MIDDLE AGES. FUNERAL LITURGY IN TWO MONASTIC CODICES FROM THE GENERAL ARCHIVE OF NAVARRE}

\begin{abstract}
One aspect of the history and historiography of death that has attracted least attention in this research area is medieval funeral liturgy. This article therefore sets out to study the structure and composition of the canonic model of the Office of the Dead based on two codices originating in Navarre, seeking to cover the ecclesiatical material deployed during and after funerals. We will thus be able to approach the canonical part of the ritual accompanying the dead, in which the Christian community of the living invoked through prayer their most important dogma: the hope of resurrection.
\end{abstract}

KEY WORDS: Medieval, Death, Funeral Liturgy, Office of the Death, Prayers.

Recibido/Received 10-04-2014

Aceptado/Accepted $\quad$ 02-06-2015

Desde época muy temprana, la Iglesia se preocupó por establecer una cobertura ceremonial respecto al momento de la muerte. ${ }^{1}$ De hecho, con anterioridad al deceso y a la intervención específica de la memoria funeraria de patronaje litúrgico, se fueron formalizando un conjunto de ritos que trascendieron la dimensión familiar y domésti-

1 Paxton, F. S. 1990. Christianizing Death: The Creation of a Ritual Process in Early Medieval Europe: 3-5, 19-27, 47-91. Ithaca and London: Cornell University Press. Mattoso, J. 1996. “Os rituais da morte na liturgia hispânica (séculos IV a IX)”, en J. Mattoso (dir.), O Reino dos mortos na Idade Média peninsular: 55-74. Lisboa: Edições João Sá da Costa. ca. ${ }^{2}$ Los vivos, de esta forma, se volcaban en sus muertos, continuando diferentes costumbres, tanto paganas - asimiladas ya desde los primeros tiempos del cristianismocomo otras surgidas de la propia doctrina de la iglesia, que fueron evolucionando a lo largo de las centurias y se

2 Baldó Alcoz, J., García de la Borbolla, A. y Pavón Benito, J. 2005. "Registrar la muerte (1381-1512). Un análisis de testamentos y mandas pías contenidos en los Protocolos Notariales Navarros". Hispania, LXV/1: 155-226, espec. 166-175. Y Baldó Alcoz, J. 2005. Requiem aeternam. Ritos, actitudes y espacios en torno a la muerte en la Navarra bajomendieval (1234-1512): 204-225. Pamplona: tesis doctoral inédita. 
integraron en la ortodoxia oficial. ${ }^{3}$ Así, los difuntos pasaron a ser el centro de atención de las actitudes y gestos de la comunidad de vivos ante esta realidad trascendental. ${ }^{4}$

Hasta la fecha, y dentro del panorama historiográfico de la historia de la muerte, resulta escasa la atención que se ha prestado a una fuente litúrgica concreta de gran valor, como es el Oficio de difuntos. ${ }^{5}$ No obstante, existen estudios significativos sobre el ordo defunctorum, esto es el ritual completo de acompañamiento al difunto en los momentos anteriores y posteriores al deceso, así como su proceso evolutivo a lo largo del medievo. Destacan los trabajos, por ejemplo, de M. Righetti. D. Sicard o F. S. Paxton, que han puesto de relieve la gestación del ritual y de la liturgia eclesiástica en torno a los muertos. Incluso, este último autor ha realizado una edición crítica de un texto De obitu fratris, et sepultura del Ordo Cluniacensis (finales del s. XI). ${ }^{6}$

Si bien el ritual funerario presenta una unidad protocolaria e ideológica de atención, cuidado y protección secuencial del enfermo, agonizante y fallecido con actuaciones y oraciones, el oficio de difuntos representa el conjunto de plegarias que pasaron a rezar las comunidades religiosas en memoria de sus difuntos durante determinados momentos del año. ${ }^{7}$ De modo que, independientemente de si hubiera habido o no un fallecimiento, se conformó un corpus de preces orientado a rogar por los muertos, que sería incorporado, a partir del siglo VII a la liturgia canónica. ${ }^{8}$

El Archivo Real y General de Navarra, situado en Pamplona, alberga una sección de Códices y Cartularios, cuyos volúmenes proceden de los diferentes archivos monásticos navarros desamortizados a raíz de las leyes de 1835 del ministro de Hacienda Juan Álvarez Mendizábal. Los fondos eclesiásticos son muy desiguales y variados, si bien mantienen cierta homogeneidad ya que se corresponden, mayoritariamente, con los lotes archivísticos de los monasterios de tradición benedictina y cisterciense de San Salvador de Leire, Santa María de Irache, Santa María de la Oliva, Santa María de Fitero, Santa María de Iranzu, San Salvador de Urdax y Santa María de la Caridad de Tulebras, y a una parte de la colección de Santa María de Roncesvalles.

3 Bastos, M. do R. 1996. "Prescrições sinodais sobre o culto dos mortos nos séculos XIII a XVI", en J. Mattoso (dir.), O Reino dos mortos na Idade Média peninsular: 109-124. Lisboa: Edições João Sá da Costa. Guiance, A. 1998. Los discursos sobre la muerte en la Castilla medieval (siglos VII-XV): 37-48. Valladolid: Junta de Castilla y León. Consejería de Cultura.

4 Mattoso, J. 1996. "O culto dos mortos no fim do século XI", en J. Mattoso (dir.), O Reino dos mortos na Idade Média peninsular: 75-85. Lisboa: Edições João Sá da Costa. Lauwers, M. 1997. La Mémoire des ancêtres le souci des morts. Morts, rites et société au Moyen Âge: 88. Paris: Beauchesne.

5 Ottosen, K. 1993. The Responsories and Versicles of the Latin Office of the Dead. Aarhus: Aarhus Universitet Press. El primero de los capítulos analiza un desarrollo histórico del tema "History of the office of the Dead": 31-49.

6 Paxton, F. S. 2013. The Death ritual at Cluny in the Central Middle Ages. Le rituel de la mort à Cluny au Moyen Âge central, Turnhout: Brepols.

7 Avril, J. 1986. "La paroisse médiévale et la priere pour les morts", en J.-L. Lemaitre (coord.), L'Église et la mémoire des morts dans la France médiévale. Communications présentées à la table Ronde du C.N.R.S. le 14 juin 1982: 53-68. Paris: Études Augustinennes.

8 Ottosen, K. 1993: 31-49.
Dentro de ese legado documental y codicológico, cabe subrayar el conjunto de volúmenes litúrgicos y bíblicos, compuesto por leccionarios, misales, calendarios litúrgicos y libros de oraciones. ${ }^{9}$ En el marco de este estudio, destacan dos manuscritos litúrgicos, los números 9 y 10, en cuyos folios finales figura - aunque incompleto-, el officium defunctorum, seguido y recitado en una comunidad de monjes, probablemente benedictinos. ${ }^{10}$ El texto, sin lugar a dudas, ilustra la cobertura desplegada para la atención espiritual, primero del moribundo y después del difunto, tanto intra claustro como para la asistencia de cualquier fiel.

El compendio de oraciones y plegarias escritas, transmitidas al calor de estas instituciones regulares, estaban concebidas para ser recitadas por los miembros de las comunidades religiosas. Debe recordarse que, a partir del siglo VIII, la oración por los difuntos entró a formar parte del oficio monástico o la disciplina de las Horas. De igual manera, el Oficio de difuntos reglamentado y compuesto por diferentes oraciones, salmos y textos bíblicos, recitado regularmente en las congregaciones, pasó a difundirse, a lo largo del siglo IX, por todos los cenobios benedictinos del Occidente Europeo. ${ }^{11}$

Las preces ante Dios - como ya advirtió San Agustín- ${ }^{12}$ ofrecían, en síntesis, los puntos de apoyo para la esperanza cristiana en el más allá y manifestaban el valor de la fe ante la caducidad de la vida y la fragilidad humana. De manera que esta pieza, el Oficio de difuntos, inserta en la liturgia de la Iglesia, codificó la plegaria de los vivos por la salvación de las almas, por lo que su estudio se convierte en un elemento de gran interés.

En esta ocasión, partiendo del modelo canónico de Oficio de difuntos, se pretende dar a conocer los corpora textuales de dos códices bajomedievales de procedencia navarra con la intención de desentrañar cómo era su estructura y su composición. Además de que se señalarán también las singularidades propias de los textos que, curiosamente, vienen acompañados de otras prácticas asociadas a la muerte como la administración de los últimos sacramentos y la relación de oraciones para la recomendación del alma. ${ }^{13}$

\section{LA INTERCESIÓN POR LOS DIFUNTOS: CURA ANIMARUM}

La oración por los muertos fue la raíz del Oficio de difuntos. Las Sagradas Escrituras revelan el origen y la causa de la muerte además de su dramatismo, aunque contraponen

9 Martinena, J. J. 1997. Guía del Archivo General de Navarra: $351-$ 352. Pamplona: Gobierno de Navarra.

10 AGN, Sección Códices y Cartularios, K. Códices litúrgicos y bíblicos, 9. Libro de oraciones (siglo XIV-XV), f. 141vo-148vo y 10 Libro de oraciones (siglo Xv), f. 90vo-103vo. En adelante, K 9 y K 10.

11 Leclercq, J. 1942. "Un ancien recueil de leçons pour les vigiles des défunts". Révue bénédictine 58: 22-24.

12 Hipona, A. de. 1995. "La piedad con los difuntos", en T. C. Martín (versión, introducción y notas), Obras completas de San Agustín. XL. Escritos varios (2ㅇ): 415-475. Madrid: Biblioteca de Autores Cristianos.

13 Queremos expresar nuestro más sincero agradecimiento al Dr. Ildefonso Adeva, canónigo de la Catedral de Pamplona y profesor de Teología de la Universidad de Navarra, por ofrecernos su inestimable ayuda y extenso conocimiento sobre la materia a la hora de analizar los textos de los dos códices litúrgicos del Archivo Real y General de Navarra. 
la esperanza de la resurrección con la victoria definitiva de Jesucristo, transformando la muerte en un principio de la vida nueva.

La Iglesia, ya desde la enfermedad y, sobre todo, momentos antes de la muerte, salía al encuentro del hombre con los sacramentos preparatorios, como así revelan los rituales funerarios. ${ }^{14}$ La piedad con los difuntos se convertía en algo más que una mera atención caritativa en el momento de la agonía y el deceso. De este modo, y dentro de un contexto religioso, la asistencia desplegada ante los fallecidos se encauzó a través de las oraciones que recitaban los vivos en tres momentos. ${ }^{15}$ El primero de ellos, tenía lugar en la casa o comunidad religiosa, durante y después de la administración de los sacramentos preparatorios; ${ }^{16}$ el segundo, quedaba formalizado en el templo, a través de las celebraciones eucarísticas; ${ }^{17}$ y el tercero, en la sepultura en el momento del sepelio. ${ }^{18}$

El consuelo y dolor de los vivos, expresión temporal de una realidad divina como era la Comunión de los Santos quedaban satisfechos a través de esta relación con los muertos, quienes a su vez desde el más allá se preocupaban de los asuntos terrenos. ${ }^{19}$ San Agustín de Hipona, ante las consultas realizadas por el obispo Paulino de Nola, acabó por escribir De cura pro mortuis gerenda, obra en la que afirmaba esa relación a dos bandas así como el socorro concreto de los mártires, intercesores directos ante la justicia divina. ${ }^{20}$ Los escritos apostólicos y la tradición eclesiástica y litúrgica de la primitiva Iglesia atestiguan la oración de los vivos por los muertos, siendo en el siglo IV cuando la oración por los difuntos aparece en el cuadro litúrgico de la Misa. ${ }^{21}$ Igualmente se documenta la práctica de vigilias la noche anterior al enterramiento, durante las cuales se recitaban lecturas bíblicas y salmos. ${ }^{22}$

De entre todos los libros de las Sagradas Escrituras, el Salterio tuvo desde la antigüedad una importancia especial. La Iglesia y sus primeros Santos Padres consideraron que las oraciones de este compendio no sólo estaban inspiradas por el Creador, sino que también tenían un contenido

\footnotetext{
14 Paxton, F. S. 1990: 38-39.
}

15 Baldó, J. 2013. “Ceremonias y espacios funerarios”, en J. Pavón Benito, J. Baldó Alcoz, A. García de la Borbolla, Pamplona y la muerte en el medievo: 74-109. Murcia: Sociedad Española de Estudios Medievales. Y Baldó Alcoz, J. 2014. "La tradición cristiana del culto a los difuntos: sufragios, misas e indulgencias", en XXIV Semana de Estudios Medievales. Ub sunt qui ante nos in hoc mundo fuere? De la tierra al cielo: 141-187, espec. 143-146. Nájera: Instituto de Estudios Riojanos.

16 Baldó Alcoz, J., García de la Borbolla, A. y Pavón Benito, J. 2005: 173-177. Baldó Alcoz, J. 2005: 209-225, 256-294. Y Baldó, J. 2013: 74-84, 91-96.

17 Baldó Alcoz, J., García de la Borbolla, A. y Pavón Benito, J. 2005: 205-212. Baldó Alcoz, J. 2005: 294-300. Pavón Benito, J. y García de la Borbolla, A. 2007. Morir en la Edad Media. La muerte en la Navarra medieval: 182-190. Valencia: Universidad de Valencia. Y Baldó, J. 2013:105-108.

18 Baldó Alcoz, J. 2005: 300-306. Y Baldó, J. 2013: 108.

19 Alexandre-Bidon, D. 1998. La Mort au Moyen Âge (XIII -XVI siècle): 109-133. Paris: Hachette.

20 De Hipona, A. 1995: 415-475.

21 Righetti, M. 1955. Historia de la Liturgia. I. Introducción General. El año litúrgico. El breviario, C. Urtasun Irisarri (edic. española): 975-977. Madrid: Editorial Católica.

22 Baldó, J. 2005: 256-265. Baldó, J. 2013: 91-96. cristológico, ya que eran la expresión más fiel de la oración del hijo de Dios. Además, los salmos, por la universalidad de los sentimientos que expresaban, eran aptos para encontrar y acoger diferentes interpretaciones a la hora de adorar y alabar al Señor. ${ }^{23}$ Se explica así la costumbre de estudiar y recitarlos entre las primeras comunidades cristianas.

La práctica de pronunciar todo el Salterio durante la vigilia de los muertos fue característica de los monasterios benedictinos ya desde el siglo VI, a tenor de los testimonios de Fulda o San Gall. Pero, dado que su lectura completa presentaba inconvenientes, fue sustituida paulatinamente por las letanías de los santos o los siete salmos penitenciales que formarían el núcleo de la Commendatio animae, fórmula litúrgica de sufragio por los difuntos ${ }^{24}$ y que se rezaba al volver del cementerio, habitualmente arrodillados en el oratorio:

Postea dicantur. VII. specialis psalmi a fratribus in oratorio prostratis. $^{25}$

Requiem eternam dona eis/ei, Domine. [Et lux perpetua luceat eis].

Pater noster. Et ne nos [inducas in tentacionem. Sed libera nos a malo].

Non intres in iudicum cum seruo/seruis tuo/tuis, Domine.

A porta inferi. [Erue, Domine, animam/animas eius/ eorum/earum].

Domine exaudi oracionem meam. [Et clamor meus ad te veniat].

Dominus uobiscum. [Et cum spiritu tuo].

Oratio. Oremus. Satisffaciat tibi, quesumus, Domine Deus noster, pro animabus fratris/fratrum nostri/nostrorum [al margen: sororis nostre], beatissime Dei genitricis Marie et sanctissimi confessoris tui Benedicti et beati Bernardi, omniumque sanctorum tuorum oratio, et presentis familie humilis supplicatio; et peccatorum omnium ueniam quam precamur obtineat/obtineant nec eum/eos paciaris cruciari gehennalibus flammis, quem/quos filii tui Domini nostri Ihesu Christi precioso sanguine redemisti. Qui tecum et cum Spiritu Sancto uiuit et regnat Deus per omnia secula seculorum. Amen.

Dominus uobiscum. [Et cum spiritu tuo].

Requiescat/requiescant in pace. Amen.

El conjunto de lecturas y salmos que se recitaban ante los muertos, en las vigilias previas a la sepultura, durante los primeros tiempos del cristianismo y, poco después en el ordo romano, acabaron por formar en los núcleos monásticos, en torno al siglo VIII, el Oficio de difuntos; un compendio perfectamente estructurado en vísperas, maitines y laudes. ${ }^{26}$ Más tarde, y a partir del siglo XI, acabaría convirtiéndose en

23 Llopis Sarrió, J. 1964. "La Sagrada Escritura. Fuente de inspiración de la liturgia de difuntos del antiguo rito hispánico". Hispania Sacra 17: 361-380.

24 Righetti, M. 1956. Historia de la Liturgia. II. La Eucaristía. Los sacramentos. Los sacramentales. Índices, C. Urtasun Irisarri (edic. española): 900-904. Madrid: Editorial Católica.

25 AGN, Sección Códices y Cartularios, K. Códices Litúrgicos y Bíblicos, 10. Libro de Oraciones (siglo Xv), f. 99vo.

26 Martimort, A. G., 1983. L'Église en prière: Introduction à la liturgie: 624. Paris: Desclée. 
la oración oficial de la Iglesia a favor de los difuntos, siendo recitada como preámbulo de la misa funeral y el sepelio en todos los ámbitos de la comunidad de fieles cristianos.

La doctrina de la Iglesia preveía, por tanto, una cobertura litúrgica, divina officia, para el hombre que se enfrentaba al fin de sus días. ${ }^{27}$ Así, se encadenó el Oficio de difuntos con los habituales sacramentos de la confesión, eucaristía - acto salvífico por excelencia- y unción -inicialmente restringido sólo a los clérigos - con la finalidad de preparar material y espiritualmente al hombre para su definitivo y último viaje. De esta forma y en su conjunto, se revivía, a la luz de las oraciones por los difuntos, la simbología del Hijo de Dios antes y en el momento de su muerte; una muerte, por otro lado, gloriosa. ${ }^{28}$

LAS PRECES DE LA IGLESIA POR SUS MUERTOS: EL OFICIO DE DIFUNTOS

El Oficio de difuntos se cantaba, independientemente del oficio canónico del día, siempre que se producía un fallecimiento en la comunidad monástica, y junto al cadáver, es decir, de cuerpo presente. Pero a partir del siglo VIII su recitación se amplió, igualmente, a la liturgia canónica siendo de obligada celebración el primer día libre del mes, o bien cada lunes de la semana; además del dos de noviembre, que era la jornada dedicada a la conmemoración solemne de todos los fieles difuntos. Su origen puede rastrearse en San Isidoro de Sevilla, que en su Regula monachorum determinaba cómo el lunes posterior a Pentecostés debería oficiarse el santo sacrificio pro spiritibus mortuorum, a semejanza de lo que se venía celebrando desde hacía tiempo en Occidente, inspirándose en la liturgia oriental que conmemoraba a los muertos el domingo siguiente a Pentecostés. También en otros establecimientos monásticos se escogían otras fechas señaladas, como la Epifanía o el aniversario del santo fundador de una iglesia, por ejemplo. ${ }^{29}$

Según se desprende de la antigua liturgia medieval, el Oficio de difuntos, que recogía una serie de oraciones por el alma de los muertos, estaba comprendido por una serie de salmos y fragmentos bíblicos, que fueron variando hasta su fijación, ya en la plena Edad Media. ${ }^{30}$ Asimismo estas plegarias se organizaban en vísperas, maitines y laudes; estructura que se encuentra recogida en los dos códices navarros que se han estudiado. Aunque únicamente aparezca de forma íntegra en el manuscrito $\mathrm{K}$ 9, como se puede observar en las tablas adjuntas, mientras que en el $\mathrm{K} 10$ faltan algunas de sus secuencias intermedias.

\section{EL REZO DE LAS VÍSPERAS}

A continuación, en las líneas siguientes, se pretende desglosar la composición de las distintas partes que componen esta plegaria a través del manejo conjunto de sendos

\footnotetext{
27 Lauwers, M. 1997: 90-100.

28 Baldó, J. 2005: 204-225.

29 Righetti, M. 1955: 982 y 1004-1008.

30 Paxton, F. S. 1990: 201-209.
}

textos. El Oficio de difuntos comenzaría, por tanto, por el rezo de las vísperas - que se recitaban por la tarde, justo antes del anochecer-, organizadas mediante cinco salmos antifonados ${ }^{31}$ seguidos por un versículo, el Magnificat con antífona. ${ }^{32}$ Asimismo, esta estructura conformada por las salmodias 114, 119, 120, 129 y 137 se fijó ya, al parecer, según ha constatado Damien Sicard, a finales del siglo IX o comienzos del siglo $\mathrm{x}^{33}$

Una parte de los salmos que se recitaban, y más en concreto: Dilexit quoniam (Ps. 114), Dominus regit me (Ps. 22), formaban parte también del ordo defunctorum, ya que se invocaban en el momento en que el alma abandonaba el cuerpo, y tras preparar el cadáver del fallecido, respectivamente. ${ }^{34}$ No obstante, cabe destacar que todas estas oraciones estaban encauzadas a motivar la esperanza ante un Dios que tendía la mano ante las miserias (Ps. 114), propias de un hombre desvalido y peregrino (Ps. 119), pero esperanzado (Ps. 120 y 129), pues el Señor se fijaba en el humilde (Ps. 137) y en el justo (Ps. 137). De ahí también la alusión al verso del Apoc. 14, 13: Bienaventurados de aquí en adelante los muertos que mueren en el Señor.

\section{[f. $\left.90 v^{\circ}\right]$ Incipit officium defunctorum. ${ }^{35}$}

A[ntiphona] ad v[espera]s s[uper] p[salmos] Placebo Domino in regione uiuorum. ${ }^{36}$ $P$ [salmus]. Dilexi, quoniam exaud[iet $].^{37}$ A[ntiphona]. Heu me quia incolatus meus prolongatus est. $^{38}$

$P$ [salmus]. Ad Dominum cum tribula[uer]. ${ }^{39}$

A[ntiphona]. Dominus custodit te ab omni malo; custodiat animam tuam Dominus. ${ }^{40}$

P[salmus]. Leuaui occulos. ${ }^{41}$

A[ntiphona]. Si iniquitates obseruaueris, Domine, Domine, quis sustinebit?. ${ }^{42}$

P[salmus]. De profundis. ${ }^{43}$

A[ntiphona]. Opera manuum tuarum, Domine, ne despicias. ${ }^{44}$

$P$ [salmus]. Confitebor. ${ }^{45}$

*Ad Magnificat antiphona: Audiui uocem de celo dicentem: Beati mortui qui in Domino moriuntur. ${ }^{46}$

Magnificat anima. ${ }^{47}$

Pater noster.

$R$ [esponsum]. Lauda, anima mea Dominum. ${ }^{48}$

\footnotetext{
31 Righetti, M. 1956: 71-76.

32 Righetti, M. 1955: 981.

33 Sicard D. 1978. La liturgie de la mort dans l'église latine des origins à la réforme carolingienne: 154-156. Münster Westfalen: Aschendorff.

34 Paxton, F. S. 1990: 39.

35 AGN, Sección Códices y Cartularios, K. Códices Litúrgicos y Bíblicos, 10. Libro de Oraciones (siglo Xv), f. 90vo

36 Psalmus (en adelante Ps.) 114,9.

37 PS. 114.

38 Ps. 119,5

39 PS. 119.

40 Ps. 120,7

41 Ps. 120,1

42 Ps. 129,3

43 Ps. 129,1

44 Ps. $137,8$.

45 Ps. 137.

46 Apoc. 14,13.

47 Luc. 1,16.

48 Ps. $145,2$.
} 


\section{Así como el Kirie:}

Dicto: "Credo in unum" bis uel ter, si adhuc superuiuerit dicatur letania. ${ }^{49}$

Kirie eleison.

Christe eleison.

Christe audi nos.

Pater de celis Deus, miserere ei.

Fili redemptor mundi Deus, miserere ei.

Spiritus Sancte Deus, miserere ei.

Sancta Trinitas unus Deus, miserere ei.

Sacta Maria, ora pro eo.

Sancta Dei genitrix, ora pro eo.

Sancta Uirgo uirginum, ora pro eo.

Sancte Michael, ora pro eo.

Este ramillete de preces, envueltas por los cinco salmos principales, manifestaba las expectativas del pueblo de Dios, colocando al hombre en una situación de inferioridad con respecto a su creador, pero también bajo su eterna misericordia. ${ }^{50}$ De ahí que esta salmodia represente con especial intensidad la visión, por parte de los mortales, del acontecimiento más importante de su existencia: el fin de sus días terrenos y el paso hacia una nueva vida. Los testamentos medievales - uno de los testimonios más elocuentes del momento- ${ }^{51}$ así lo reflejan y recogen, pues mujeres y hombres de distinta naturaleza desplegaron sus creencias ante dicha realidad, consignándolas por escrito. De un lado se sabían de la mano de Dios, pero al mismo tiempo fomentaban todo tipo de actuaciones para unirse al sacrificio de Cristo, único acto redentor y camino de salvación. Por ello encargaban oraciones, misas y se volcaban en la atención con los más necesitados en sus últimas mandas protocolarias. ${ }^{52}$

\section{LOS MAITINES}

Por otro lado, y volviendo al corpus analizado, la ordenación de estos manuscritos presenta una singularidad, ya que entre el Magnificat de las vísperas y el Kirie, el último texto que se recoge, se inserta el Oficio divino de maitines, que es la primera de las horas canónicas, rezada al amanecer. Esta parte está formada, asimismo, por tres nocturnos, que son cada una de las partes del oficio, y a su vez se componen de antífonas, salmos y lecciones.

Los tres nocturnos, o vigilias, comenzaban directamente, sin invitatorio, siendo cantados en cada uno de ellos, primero tres salmos antifonados - esto es, salmo seguido de su correspondiente antífona-, después tres lecciones tomadas

49 AGN, Sección Códices y Cartularios, K. Códices Litúrgicos y Bíblicos, 9. Leccionario (siglos XIV-XV), f. 148Vo.

50 Paxton, F. S. 1990: 42.

51 Pavón Benito, J. 2014. "La última escritura. La aparición y el desarrollo de la práctica testamental", en XXIV Semana de Estudios medievales. Ubi sunt qui ante nos in hoc mundo fuere? De la tierra al cielo: 217-237. Nájera: Instituto de Estudios Riojanos.

52 Baldó, J. 2005: 203-209, 256-320, 665-676, 693-729. Baldó Alcoz, J. 2006. "Segunt a mi estado fazer pertenesce. Imagen y memoria de los grupos sociales privilegiados en la Navarra bajomedieval: el cortejo funerario", en VI Congreso de Historia de Navarra, 19-22 de Septiembre de 2006. Pamplona. Navarra: Memoria e Imagen II: 391-394, Pamplona: Sociedad de Estudios Históricos de Navarra (SEHN). Pavón Benito, J. y García de la Borbolla, A. 2007: 138-150. Baldó, J. 2013: 96-100, 109-116. Y Baldó, J. 2014: 145-147, 155-156. del libro de Job - componiendo un total de nueve- y finalmente, tras cada una de ellas, era recitado un responsorio, también tomado del mismo libro. ${ }^{53} \mathrm{Al}$ igual que las vísperas, la ordenación de los salmos y la introducción de los fragmentos de las lecciones de los nocturnos siguen los modelos de los ordines romanos, presentes en distintos manuscritos altomedievales (fines s. IX-comienzos s. X)..$^{54}$

In primo nocturno. ${ }^{55}$

Antiphona. Dirige, Domine Deus meus in conspectu tuo uiam meam. ${ }^{56}$

Psalmus. Uerba mea. ${ }^{57}$

Antiphona. Conuertere, Domine, et eripe animam meam quoniam non est in morte qui memor sit tui. ${ }^{58}$

Psalmus. Domine, ne in furore tuo. ${ }^{59}$

Antiphona. Nequando rapiat ut leo animam meam, dum non est qui redimat neque qui saluum faciat. ${ }^{60}$

Psalmus. Domine Deus meus. ${ }^{61}$

Versus. Anima mea turbata est ualde, [sed tu, Domine, succurre ei].

\section{Lectio prima. [f. $142 r^{\circ}$ ]}

Parce mihi, Domine, nichil enim sunt dies mei. Quid est homo quia magnificas eum, aut quid apponis erga eum cor tuum? Uisitas eum diluculo, et subito probas illum, usque quo non parcis mihi. nec dimittis me ut gluciam saliuam meam? Peccaui. Quid faciam tibi, o custos hominum? Quare posuisti me contrarium tibi, et factus sum mihi metipsi grauis? Cur non tollis peccatum meum, et quare non aufers iniquitatem mea? Ecce nunc in puluere dormiam. et si mane me quesieris non subsistam. ${ }^{62}$

Responsum. Credo quod redemptor meus uiuit et in nouissimo die de terra surrecturus sum et in carne mea uidebo Deum saluatorem meum, versus Quem uisurus sum ego ipse et non alius et occuli mei conspecturi [sunt] Et in car[ne...].

\section{Lectio secunda}

Tedet animam meam uite mee, dimittam aduersum me eloquium meum. Loquar in amaritudine anime mee, dicam Deo: Noli me condempnare. Indica mihi, cur me iudices. Numquid bonum tibi uidetur, si calumpnieris et opprimas me, opus manuum tuarum, et consilium impiorum adiuues? Numquid occuli carnei tibi sunt, aut sicut uidet homo et tu uides? Numquid sicut dies hominis dies tui, et animi tui sicut humana sunt tempora, ut queras iniquitatem meam et peccatum meum scruteris, et scias [f. 142vo] quia nichil impium fecerim cum sit nemo qui de manu tua possit eruere?. ${ }^{63}$

Responsum. Qui Lazarum resuscitasti a monumento fetidum, tu eis, Domine dona requiem Et locum indulgentie. Versus Requiem eternam dona eis Domine, et locum. [...]

53 Righetti, M. 1955: 981. Y Righetti, M. 1956: 245-249.

54 Sicard D. 1978: 156-162.

55 AGN, Sección Códices y Cartularios, K. Códices Litúrgicos y Bíblicos, 9. Leccionario (siglos XIV-XV), f. 141vo-144vo

56 Ps. 5,9.

57 PS. 5.

58 PS. 6,6.

59 Ps. 6.

60 PS. 7,3.

61 PS. $7,4$.

62 Job 7,16-21.

63 Job 10, 1-7. 
Lectio tercia.

Manus tue fecerunt me et plasmauerunt me totum in circuitu. et sic repente precipias me? Memento, queso, quod sicut lutum feceris me, et in puluerem reduces me. Nonne sicut lac mulsisti me. et sicut caseum me coagulasti? Pelle et carnibus uestisti me, ossibus et neruis compegisti me. Uitam et misericordiam tribuisti michi, et uisitacio tua custodiuit spiritum meum. ${ }^{64}$

Responsum. Memento mei, Deus, quia uentus est uita mea. Nec aspiciet me uisus hominis. Versus. Et non reuertetur occulus meus ut uideat bona Nec aspici[et].

\section{In II nocturno.}

A[ntiphona]. In loco Paschue ibi me collocauit. ${ }^{65}$

Psalmus. Dominus regit me. ${ }^{66}$

A[ntiphona]. Delicta iuuentutis me et ignorancias meas ne memineris, Domine. ${ }^{67}$

Psalmus. Ad te, Domine leua[ui].68

Antiphona. Credo uidere bona Domini in terra uiuentium. ${ }^{69}$

Psalmus. Dominus illuminatio. ${ }^{70}$

Versus. Conuertere, Domine, et eripe animam meam. ${ }^{71}$

\section{Lectio Quarta}

Responde mihi. Quantas habeo iniquitates et peccata; scelera mea et delicta ostende mihi. Cur faciem tuam abscondis; et arbitraris me inimicum tuum? Contra folium quod uento rapitur ostendis potenciam tuam; et stipulam siccam prosequeris. Scribis enim [f. 143ro en el margen superior del manuscrito y con otra letra: benedicite omnia opera Domini Domino] contra me amaritudines; et consummere me uis peccatis adolescentie mee. Potuisti in neruo pedem meum; et obseruasti omnes semitas meas et uestigia pedum meorum considerasti. Qui quasi putredo consumendus sum. et quasi uestimentum quod comeditur a tinea. ${ }^{72}$

Responsum. Heu mihi, Domine, quia peccaui nimis in uita mea; quid faciam miser, ubi fugiam, nisi ad te, Deus meus? miserere mei dum ueneris in nouissimo die. Versus. Anima mea turbata est ualde, sed tu, Domine, sucurre ei. In nouis[simo].

\section{Lectio quinta}

Homo natus de muliere, breui uiuens tempore, repletur multis miseriis. Qui qui quasi flos egreditur et conteritur et fugit uelut umbra; et nunquam in eodem statu permanet. Et dignum ducis super huiuscemodi aperire occulos tuos; et aducere eum tecum in iudicium? Quis potest facere mundum de in mundo conceptum semine? Nonne tu qui solus es? Breues dies hominis sunt; numerus mensium eius apud te est. Constituisti terminos eius qui preteriri non poterunt. Recede paululum ab eo, ut quiescat donec optata ueniat, sicut mercennarii, dies eius. ${ }^{73}$
Responsum. Ne recorderis peccata mea, Domine, Dum ueneris iudicare secundum per ignem. Versus. Non intres in iudicium cum seruis tuis, Domine. Dum.

\section{Lectio sexta}

Quis mihi hoc tribuat ut in inferno protegas me. et abscondas me donec pertranseat furor tuus; et constituas mihi tempus in quo recorderis mei? Putasne [f. 143vo] mortuus homo rursum uiuat? Cunctis diebus quibus nunc milito, expecto donec ueniam inmutacio mea. Uocabis me, et ego respondebo tibi; operi manuum tuarum porriges dexteram. Tu quidem gressus meos dinumerasti; sed parce peccatis meis. ${ }^{74}$

Responsum. Libera me, Domine, de uiis inferni. Qui portas ereas confregisti et uisitasti infernum et dedisti eis lumen ut uiderent te qui erant in penis tenebrarum. Versus Clamantes et dicentes: aduenisti, redemptor noster. Qui portas.

\section{In III nocturno}

Antiphona. Complaceat tibi, Domine, ut eruas me, ad adiuuandum me respice..$^{75}$

Psalmus. Expectans [exspecatui Dominum]. ${ }^{76}$ tibi. ${ }^{77}$

Antiphona. Sana, Domine, animam meam quia peccaui

Psalmus. Beatus qui intelligit. ${ }^{78}$

Antiphona. Sitibit anima mea ad Deum uiuum; quando ueniam et apparebo ante faciem Domini. ${ }^{79}$

Psalmus. Quemadmodum [desiderat cervus ad fontes]..$^{80}$

Versus. In memoria eterna erit iustus. ${ }^{81}$

\section{Lectio Septima}

Spiritus meus attenuabitur; dies mei breuiabuntur; et solum mihi superest sepulcrum. Non peccavi; et in amaritudinibus moratur occulus meus. Libera me et pone me iuxta te; et cuiusuis manus pugnet contra me. [...] Dies mei transierunt; cogitaciones [m]ee dissipate sunt, torquentes cor meum. Noctem uerterunt in diem; et rursum post tenebras spero lucem. Si sustinuero, infernus domus mea est; et in tenebris straui lectulum meum. Putredini dixi: Pater meus es; mater mea, et soror mea, uermibus. Ubi est ergo nunc prestolacio [f. 144ro] mea? et pacientia mea? Tu es, Domine Deus meus. ${ }^{82}$

Responsum. Peccante ${ }^{83}$ me cotidie et non me penitente, ${ }^{84}$ timor mortis conturbat me. Quia in inferno nulla est redemptio. Miserere mei, Deus, et salua me. Versus. Deus, in nomine tuo saluum me fac et in uirtute tua libera me. Quia.

\section{Lectio octaua}

Pelli mee, consumptis carnibus, adhesit os meum; et derelicta sunt tantummodo labia circa dentes meos.

\footnotetext{
64 Job 10, 8-12.

65 Ps. 22, 1.

66 Ps. 22.

67 Ps. 24,7.

8 PS. 24.

69 Ps. 26,13.

70 Ps. 26.

Ps. 6,5.

Job 13, 22-28.

Job 14, 1-6.
}

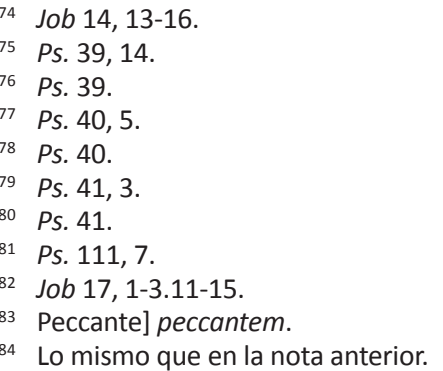


Miseremini mei, miseremini mei, saltem uos, amici mei; quia manus Domini tetigit me. Quare persequimini me sicut Deus, et carnibus meis saturamini? Quis mihi tribuat ut scribantur sermones mei? Quis michi det ut exarentur in libro stilo ferreo, et plumbi lamina; uel celte sculpantur in silice? Scio enim quod redemptor meus uiuit, et in nouissimo die de terra surrecturus sum; et rursum circundabor pelle mea; et in carne mea uidebo Deum, saluatorem meum. Quem uisurus sum ego ipse; et occuli mei conspecturi sunt; et non alius. Reposita est hec spes mea in sinu meo. ${ }^{85}$

Responsum Domine, secundum actum meum noli me iudicare; nichil dignum in conspectu tuo egi. Ideo deprecor maiestatem tuam ut tu Deus deleas iniquitates meas. Versus. Amplius laua me, Domine, ab iniusticia mea et a delicto meo munda me; tibi soli peccaui. Ideo.

\section{Lectio nouena}

Uir fortissimus Judas, [...] collatione facta [f. 144vo] duodecim milia dragmas argenti, misit Iherosolimam offerri ea ibi pro peccatis mortuorum, iuste et religiose de resurreccione cogitans. Nisi enim eos qui ceciderant resurrecturos speraret, superfluum uideretur et uanum orare pro mortuis. Et quia considerabat, quod hii qui cum pietate dormicionem acceperant, optimam haberent repositam gratiam. Sancta ergo et salubris est cogitacio pro defunctis exorare, ut a peccatis soluantur.

Responsum. Libera me, Domine, de morte eterna in die illa tremenda Quando celi mouendi sunt et terra. Dum ueneris iudicare seculum per ignem. Versus. Dies illa, dies ire, calamitatis et miserie, dies magna et amara ualde. Quando ce[li]. Versus. Tremens factus sum ego et timeo, dum discussio venerit atque uentura ira. Dum ue[neris]. Versus. Quid ego miserrimus, quid dicam uel quid faciam, dum nihil boni proferam ante tantum iudicem? Responsum. Libera me, Domine. ${ }^{86}$

El noveno responsorio se correspondía durante el siglo $\mathrm{XI}$, con Ne recorderis peccata mea pero, posteriormente, fue sustituido por Libera me, Domine que es el que aparece en los manuscritos estudiados $-y$ está reproducido en el párrafo anterior, como ya se ha visto-. R. Rutherford señala que este responsorio, comenzado a aplicarse a partir del siglo XII, está en relación con la acentuación de la solicitud, en las comunidades monásticas, del perdón divino. ${ }^{87}$

Los nocturnos, como las vísperas, alentaban la confianza de aquellas comunidades monásticas medievales que rezaban, en cierta manera representando las creencias de una buena parte de los hombres de aquella época. Sus oraciones, sus salmos, volvían sobre la idea de un Dios todopoderoso que acudía a la llamada de los justos (Ps. 5, 6, 7, 111) a quienes conducía por el buen camino y protegía (Ps. 22, 24, 26), saciándoles y preservándolos de todo mal (Ps. 39, $40,41)$. Además las plegarias estaban acompañadas por fragmentos del libro de Job (Job 7, 10, 13, 14 y 17), capítulo bíblico que contiene el más hondo y desgarrado de los cantos de la humanidad a la esperanza divina. Su ejemplo gestó un modelo cultural de paciencia, perseverancia $y$, finalmente, de clemencia de un Padre que no se olvidaba nunca de su pueblo.

85 Job 19, 20-27.

86 Se repite hasta el versus.

87 Rutherford, R. 1980. The Death of a Christian: The rite of funerals: 61-62. New York: Pueblo Pub. Co.

\section{LAUDES}

Tras el oficio de maitines se insertó en el códice la denominada primera víspera, que según D. Sicard, formaba parte de las plegarias de laudes, a tenor de los salmos elegidos, así como el canto de Ezequías. ${ }^{88}$

\section{In I vesperis ${ }^{89}$}

A[ntiphona]. Exultabunt Domino ossa humilitata. ${ }^{90}$ Psalmus. Miserere mei, Deus. ${ }^{91}$

Antiphona. Exaudi, Domine, oracionem meam; ad te omnis caro veniet. ${ }^{92}$

Psalmus. Te decet. ${ }^{93}$

Antiphona. Me suscepit dextra tua, Domine. ${ }^{94}$

Psalmus. Deus, Deus meus. ${ }^{95}$

Antiphona. Eruisti, Domine, animam meam ne periret. ${ }^{96}$ Psalmus. Ego dixi.

Antiphona. Omnis spiritus laudet Dominum. ${ }^{97}$

Psalmus. Laud[ate] Dominum de celis. ${ }^{98}$

Ad Benedictus. Antifona. Ego sum resurrectio et uita qui credit in me etiam si mortuus fuerit uiuet, et omnis qui credit in me, non morietur in eternum.

Psalmus. Benedictus Dominus..$^{99}$ [145 ro. .]

Pater noster. [Et ne nos inducas in tentationem. Sed libera nos a malo]

Psalmus. De profundis. ${ }^{100}$

Requiem eternam [dona ei/eis, Domine. Et lux perpetua luceat ei/eis].

A porta inferi. [Erue, Domine, animam/animas eius/ eorum/earum].

Dominus uobiscum. [Et cum spiritu tuo].

Oremus.

Al igual que en el resto de las horas canónicas, los laudes trasmiten esperanza a pesar de la poquedad de un hombre débil por su naturaleza caída (Ps. 50 Miserere), ante un Dios que escucha las plegarias de quien le busca, tendiéndole su mano (Ps. 64,3 y 62,9). Por ello merece la alabanza de todas las criaturas (Ps. 148 y 150), pues ha cargado sobre sus espaldas el peso del pecado (Isaías 38,17 ).

\section{OTRAS PLEGARIAS FUNERARIAS}

El oficio de difuntos, fijó, en última instancia, una serie de oraciones diversas en favor de diferentes grupos de difuntos y aplicadas a distintas celebraciones religiosas.

Incipiunt collecte in anniuersariis defunctorum ${ }^{101}$

Presta, Domine, quesumus, ut anime famulorum tuorum quorum anniuersarium depositionis diem conmemoramus;

88 Sicard D. 1978: 163-164.

89 AGN, Sección Códices y Cartularios, K. Códices Litúrgicos y Bíblicos, 9. Leccionario (siglos XIV-XV), f. 144vo--145ro.

90 Ps. 50, 10.

91 PS. 50.

92 Ps. 64,3.

93 Ps. 64.

94 Ps. 62, 9.

95 Ps. 62.

96 Isaias 38, 17.

97 Ps. 150, 6.

98 PS. 148.

99 PS. 143.

100 Ps. 129.

101 AGN, Sección Códices y Cartularios, K. Códices Litúrgicos y Bíblicos, 9.Leccionario (siglos XIV-XV), f. 145rํ-ㄴo. 
indulgentiam pariter et requiem capiant sempiternam. P[er Dominum...]

\section{Alia collecta pro defunctis}

Inclina, Domine, aurem tuam ad preces nostras, quibus misericordiam tuam supplices deprecamur; ut animas famulorum famularumque tuarum. quas de hoc seculo migrare iussisti. in pacis ac lucis regione constituas; et sanctorum tuorum iubeas esse consortes. Per [Dominum...]

\section{Pro femina defuncta}

Quesumus, Domine, pro tua pietate miserere animabus famularum tuarum et a contagiis mortalitatis erutas, ${ }^{102}$ in eterne saluationis partem restitue. Per [Dominum...]

\section{Pro fratribus aggregationis}

Deus uenie largitor et humane saluctis auctor, quesumus clementiam tuam, ut nostre congregationis fratres et familiares qui ex hoc seculo transsierunt, beata Maria semper uirgine intercedente cum omnibus sanctis, ad perpetue beatitudinis consorcium peruenire [concedas. Per Dominum...]

\section{Pro episcopo collecta}

Deus qui inter apostolicos sacerdotes famulum tuum. N. pontificali fecisti dignitate uigere; presta, quesumus, ut eorum quoque perpetuo aggregetur consorcio

\section{[f. 145v으 In anniuersario cotidiano defunctorum}

Deus, cui proprium est misereri semper et parcere, propiciare animabus famulorum famularumque tuarum, et omnia eorum peccata dimitte; ut mortis uinculis absoluti, transire mereantur ad uitam. Per [Dominum...]

\section{Alia collecta}

Omnipotens sempiterne Deus, cui nunquam sine spe misericordie supplicatur, propiciare animabus famulorum famularumque tuarum, ut qui de hac uita in tui nominis confessione discesserunt, sanctorum tuorum numero facias aggregari. Per [Dominum...].

\section{Alia collecta}

Fidelium Deus omnium conditor et redemptor, animabus famulorum famularumque tuarum, remissionem cunctorum tribue peccatorum ut indulgentiam quam semper optauerunt, piis supplicationibus consequantur. Per Dominum nostrum. et cetera.

La oración dominical actuaba como remate y conclusión del Oficio, aunque en el caso del manuscrito $\mathrm{K} 9$ dicha oración ha sido, tal y como se ha comentado anteriormente, un $\mathrm{Credo}^{103}$ y el Kirie. Mientras que en el códice K 10 la oración que culminaba el Oficio de difuntos era el rezo de los siete salmos penitenciales.

\footnotetext{
102 Erultas] sic.

103 Righetti, M. 1956: 256-260.
}

Para finalizar, es necesario señalar que, en ambos casos, fueron agregados - se interpolaron en el caso del manuscrito K10 o se añadieron al final del ejemplar K 9- otros textos de carácter litúrgico. En concreto, un breve ordo defunctorum, que tenía por objeto la preparación previa a la muerte de los miembros de la comunidad, tal y como se indica y describe en las tablas adjuntas. Dichos añadidos recogían la forma de acompañar al moribundo y de aplicar los sacramentos en el momento de la agonía (confesión, unción de enfermos o extremaunción, comunión o eucaristía y recomendación del alma). ${ }^{104}$ Asimismo, y sólo en el manuscrito $K 10$, se incluyen las ceremonias y oraciones de la comunidad tras el fallecimiento consistentes en la bendición del cadáver y del sepulcro y en la recitación de plegarias, tanto por el muerto como por el resto de difuntos, que serían celebradas primero en el cementerio y posteriormente en el templo.

\section{REFLEXIONES FINALES}

El lenguaje de los signos y símbolos de la Edad Media estaba constituido por un complejo y completo universo de elementos capaces de recrear y recoger las imágenes, creencias y vivencias también, lógicamente, en relación a la muerte. La dimensión antropológica y cultural de aquellas centurias estuvo sostenida principalmente por el teocentrismo. El mundo se concebía como una imagen de Dios, creador de la realidad articulada simbólicamente mediante signos materializados en el orden gestual, litúrgico, ritual y artístico de cualquier plano de la existencia. Dichos signos, además, lograban no sólo evocar una realidad trascendente, sino acercar el mundo terrestre y el celeste.

La sociedad medieval otorgó una gran importancia al conjunto de los ritos litúrgicos que acompañaban los últimos y postreros momentos del fin de la vida. El conjunto de intenciones, anhelos y necesidades del hombre quedaban cubiertos y respaldados por la Iglesia que, constituida en mediadora entre Dios y los hombres, supo recoger y modelar, a través de los sacramentos y oficios religiosos, un conjunto de símbolos cercanos y muy representativos para el despliegue de la liturgia, esto es, el lenguaje divino para con los hombres. Por tanto, la liturgia, en su acepción de ecclesiastica officia, codificó las imágenes alegóricas del hombre medieval dando lugar a signos desplegados en el conjunto de la sociedad. De una manera general, se articuló una gran variedad tipológica de símbolos, eficaces en tanto que lograban transmitir conocimientos y programas morales para la vida material y espiritual de la comunidad humana.

104 Righetti, M. 1956: 898-899 (asistencia a enfermos); 824-831 (confesión) y 837-838; 879-898 (unción de enfermos, extremaunción); 740 (Eucaristía); 900-904 (recomendación del alma). Adeva Martín, A. 1992. "Cómo se preparaban para la muerte los españoles a finales del siglo XV". Anuario de Historia de la Iglesia 1: 118-120. Guiance, A. 1998: 48-60. Y Adeva Martín, A. 2002. "Ars bene moriendi. La muerte amiga", en J. Aurell y J. Pavón (eds.), Ante la muerte. Actitudes, espacios y formas en la España medieval: 295-360. Pamplona: EUNSA. 
Las experiencias, conocimientos y consideraciones de la muerte que, por ejemplo, transmiten las plegarias del Oficio de difuntos, se integraban simbólicamente en un código de representaciones, como el temor de Dios, la necesidad de purgar el pecado y la fugacidad de la vida. Estas imágenes, propias del paradigma cultural del aquella etapa histórica, compusieron un entramado de analogías capaz de propiciar la adecuación de una serie de mensajes religiosos sobre un variado panorama social. Y, asimismo, se convirtieron en el vehículo idóneo para expresar todo aquello que conformaba las disquisiciones espirituales y vivencias religiosas en torno a la muerte.

El Oficio de difuntos, que acompañaba y daba sentido a la liturgia específicamente sacramental (unción, comunión, misas) se identificaba, en suma, con la cobertura litúrgica preparada en la tradición de la Iglesia en forma de rogativas. Estas preces, asimismo, revelaban la concepción cristiana de la muerte latente en la sociedad medieval, tanto en forma de propuesta eclesiástica como de instrumento idóneo que recogía las creencias de la comunidad de fieles. La difusión de este repertorio a partir del siglo VIII, con oraciones variadas, e inicialmente inscrito en las comunidades religiosas, formalizó el dolor ante la muerte y la confianza cristiana por alcanzar la casa de Dios. ${ }^{105} \mathrm{Y}$ dio lugar a la elaboración de una serie de textos rituales, muchos de los cuales conforman hoy el legado de la cultura medieval.

\section{TABLA 1}

A continuación se presenta una tabla en la que se recoge la organización que originalmente tenían estos dos códices, tal y como fueron encuadernados. En realidad, no siguen la disposición correcta de las lecciones y oficios que se desarrollaban en la Misa, como tampoco la que tenía lugar en el Oficio de difuntos, sobre todo en el caso del manuscrito K 10, que está particularmente desordenado.

\begin{tabular}{|c|c|}
\hline MANUSCRITO K 9 & MANUSCRITO K 10 \\
\hline $\begin{array}{l}\text {-Incipit officium defunctorum ad vesperas super } \\
\left.\text { psalmos (f. } 141 v^{\circ}\right)\end{array}$ & $\begin{array}{l}\text {-Incipit officium defunctorum. Ad vesperas s[uper] p[salmos]. } \\
\text { A[antiphona] (f. } 90 \mathrm{v}^{\circ}-91 \mathrm{r}^{\circ} \text { ) }\end{array}$ \\
\hline Lectio prima (f. $142 r^{\circ}$ ) & Lectio prima (f. $\left.91 r^{\circ}\right)$ \\
\hline Lectio secunda (f. $\left.142 r^{\circ}-v^{\circ}\right)$ & Lectio secunda (f. $\left.91 r^{\circ}\right)$ \\
\hline Lectio tercia (f. $\left.142 v^{\circ}\right)$ & Lectio III (f. $\left.91 r^{\circ}-v^{\circ}\right)$ \\
\hline Lectio Quarta (f. $142 v^{\circ}-143 r^{\circ}$ ) & Lectio IIII (f. $\left.91 \mathrm{v}^{\circ}\right)$ \\
\hline Lectio quinta (f. $143 r^{\circ}$ ) & $\begin{array}{l}\text { Lectio } V\left(\mathrm{f} .91 v^{\circ}-92 r^{\circ} \text { ) fragmento y corte. Se retoma el Oficio de }\right. \\
\text { difuntos en el f. } 103 r^{\circ} \text { continuando con la última parte de la Lectio } \\
\text { IX y enlazando con la Primera Víspera }\end{array}$ \\
\hline Lectio sexta (f. $\left.143 r^{\circ}-v^{\circ}\right)$ & $\begin{array}{l}\text { Inserción de las invocaciones y oraciones posteriores al Benedictus } \\
\left.\text { de Laudes. Falta todo el apartado anterior (f. } 92 r^{\circ}-{ }^{-}-\text {o }\right)\end{array}$ \\
\hline Lectio Septima (f. $143 v^{\circ}-144 r^{\circ}$ ) & $\begin{array}{l}\text { Qvando infirmus morti penitus apropinquauerit, percuciatur } \\
\text { tabula crebris ictibus; quo audito, omnes fratres, relictis omnibus } \\
\text { que in manibus habuerint, accurrant uelociter ad morientem } \\
\text { dicentes: Credo in unum Deum. Repetentes illud bis uel ter, si } \\
\text { necesse fuerit. Si autem adhuc superuixerit, dicatur letania ista. } \\
\text { Recomendación del alma (f. } 93 r^{\circ}-95 r^{\circ} \text { ) }\end{array}$ \\
\hline Lectio octaua (f. $144 \mathrm{r}^{\circ}$ ) & \multirow{5}{*}{ 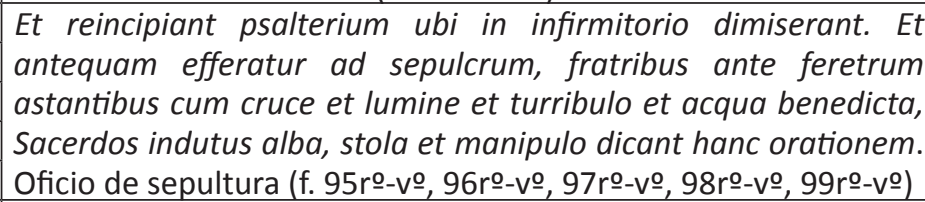 } \\
\hline Lectio nouena (f. $144 \mathrm{r}^{\circ}-\mathrm{v}^{\circ}$ ) & \\
\hline Incipiunt collecte in anniuersariis defunctorum (f. $145 r^{\circ}$ ) & \\
\hline Allia collecta pro defunctis (f. $145 r^{\circ}$ ) & \\
\hline Pro femina defuncta (f. $145 r^{\circ}$ ) & \\
\hline Pro fratribus aggregationis (f. $145 \mathrm{r}^{\circ}$ ) & $\begin{array}{l}\text { Postea dicantur. VII. specialis psalmi a fratribus in oratorio } \\
\text { prostratis. Rezo de los siete salmos penitenciales (f. } 99 \mathrm{v}-100 \text { ro) }\end{array}$ \\
\hline Pro episcopo collecta (f. 145 ro) & $\begin{array}{l}\text { Que sunt instrumenta bonorum operum. Resumen ascético de } \\
\text { vida cristiana (f. 100ro-100vㅇ) }\end{array}$ \\
\hline In anniuersario cotidiano defunctorum (f. $145 \mathrm{v}^{\circ}$ ) & Intercalación de oficio de sepultura (f. 101rㅇ-ํo, 102rㅇ--vo) \\
\hline Allia collecta (f. $145 \mathrm{v}^{\circ}$ ) & Lectio IX (f. 103r ${ }^{\circ}$ ) (Parte final de la misma) \\
\hline Allia collecta (f. $145 v^{\circ}$ ) & $-\left[I N /\right.$ VESPERIS] (f. $\left.103 r^{\circ}\right)$ \\
\hline Quomodo inungantur infirmi (f. 146ro) & Incipiunt orationes pro defunctis (f. $103 r^{\circ}$ ) \\
\hline Oremus (f. 146ro-vo) (unción) & In anniuersario defuncti (f. $103 r^{\circ}$ ) \\
\hline Oracio (f. 146vㅇ-147r으) & Allia collecta pro defunctis (f. $103 r^{\circ}$ ) \\
\hline Oracio (f. 147rㅇ-147vo) & Pro fratribus aggregationis defunctis (f. $103 r^{\circ}$ ) \\
\hline Alia oracio (f. $147 \mathrm{v}$ - $)$ & In [a]nniuersario cotidiano pro d[efunctis] (f. $103 r^{\circ}-v^{\circ}$ ) \\
\hline $\begin{array}{l}\text { Dos folios añadidos (f. } 148 \mathrm{r}-\text { y } 148 \mathrm{v} \text {-) en los que se } \\
\text { recogen distintas oraciones y ceremoniales relaciona- } \\
\text { dos con el ritual de la extremaunción y muerte aplicado } \\
\text { a frailes de una comunidad conventual }\end{array}$ & Allia collecta... (f. $103 v^{\circ}$ ) \\
\hline
\end{tabular}

105 Sicard D. 1978: 414-418. 
TABLA 2

Esta segunda relación recoge la organización correcta que deberían haber seguido los dos códices, en función de la disposición de los textos litúrgicos oficiales. Las tareas de corrección y ordenación de los dos ejemplares $\mathrm{K} 9$ y $\mathrm{K} 10$ fueron efectuadas por el Dr. I, Adeva Martín. En ella se puede observar cómo el códice K 9 presta mayor atención al aspecto preparatorio de la muerte y le dedica un mayor número de páginas, frente al manuscrito K 10 que presenta un mayor interés por el funeral, entierro y preces post anima en auxilio del alma del difunto. Por lo tanto, uno complementa al otro en composición y contenido, dando entre ambos una secuencia organizada bastante aproximada de todo el ritual funerario y de la liturgia de difuntos, aplicada tanto al momento de la muerte como a la memoria posterior hacia los difuntos en la liturgia cotidiana y específica de la Iglesia.

\begin{tabular}{|c|c|}
\hline MANUSCRITO K 9 & MANUSCRITO K 10 \\
\hline -INCIPIT OFICCIUM DEFUNCTORUM (f. $141 v^{\circ}$ ) & -INCIPIT OFICCIUM DEFUNCTORUM (f. 90vº) \\
\hline Antiphona ad vesperas super psalmos (f. $141 v^{\circ}$ ) & A[ntiphona] ad v[espera]s s[uper] p[salmos] (f. $\left.90 v^{\circ}\right)$ \\
\hline -IN PRIMO NOCTURNO (f. $141 v^{\circ}$ ) & -IN PRIMO NOCTURNO (Maitines) (f. 90vำ-91r으) \\
\hline Lectio prima (f. $142 r^{\circ}$ ) & Lectio prima (f. $91 r^{\circ}$ ) \\
\hline Lectio II (f. $\left.142 r^{\circ}-v^{\circ}\right)$ & Lectio secunda (f. $91 r^{\circ}$ ) \\
\hline Lectio III (f. $\left.142 v^{\circ}\right)$ & Lectio III (f. $\left.91 r^{\circ}-v^{\circ}\right)$ \\
\hline -IN II NOCTURNO (f. $142 v^{\circ}$ ) & 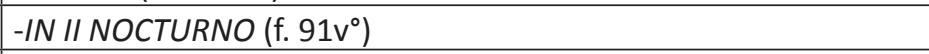 \\
\hline Lectio IIII (f. $\left.142 v^{\circ}-143 r^{\circ}\right)$ & Lectio IIII (f. $\left.91 \mathrm{v}^{\circ}\right)$ \\
\hline Lectio $V\left(f .143 r^{\circ}\right)$ & \multirow{5}{*}{$\begin{array}{l}\text { Lectio } V\left(\mathrm{f} .91 v^{\circ} \text { ) En el f. } 92 r^{\circ} \text { se produce un corte y un cambio de }\right. \\
\text { tema. En el f. } 103 r^{\circ} \text { se retoma el Oficio de difuntos continuando } \\
\text { con la parte final de la lección novena, enlazando con la Primera } \\
\text { Víspera) }\end{array}$} \\
\hline Lectio VI (f. $\left.143 r^{\circ}-v^{\circ}\right)$ & \\
\hline$-I N$ III NOCTURNO (f. $143 v^{\circ}$ ) & \\
\hline Lectio VII (f. $\left.143 v^{\circ}-144 r^{\circ}\right)$ & \\
\hline Lectio VIII (f. $144 \mathrm{r}^{\circ}$ ) & \\
\hline Lectio IX (f. $\left.144 v^{\circ}\right)$ & Lectio IX (f. $\left.103 r^{\circ}\right)$ (sólo la parte final de la misma: el responso) \\
\hline$-I N$ I VESPERIS (f. $144 v^{\circ}-145 r^{\circ}$ ) & $-I N /$ VESPERIS (f. $103 r^{\circ}$ ) \\
\hline $\begin{array}{l}\text { Incipiunt collecte in anniuersariis defunctorum (f. } \\
145 \mathrm{r}^{\circ} \text { ) }\end{array}$ & Incipiunt orationes pro defunctis (f. $103 r^{\circ}$ ) \\
\hline Allia collecta pro defunctis (f. $145 \mathrm{r}^{\circ}$ ) & In anniuersario defuncti (f. $103 r^{\circ}$ ) \\
\hline Pro femina defuncta (f. $145 \mathrm{r}^{\circ}$ ) & Allia collecta pro defunctis (f. $103 r^{\circ}$ ) \\
\hline Pro fratribus aggregationis (f. $145 \mathrm{r}^{\circ}$ ) & Pro fratribus aggregationis defunctis (f. $103 r^{\circ}$ ) \\
\hline In anniuersario cotidiano defunctorum (f. $145 \mathrm{v}^{\circ}$ ) & [In an]niuersario cotidiano pro defunctis (f. $103 r^{\circ}-v^{\circ}$ ) \\
\hline Allia collecta (f. $145 v^{\circ}$ ) & Allia collecta... (f. $103 v^{\circ}$ ) \\
\hline Allia collecta (f. $\left.145 v^{\circ}\right)$ & $\begin{array}{l}\text { Invocaciones y oraciones posteriores al Benedictus de Laudes (f. } \\
92 \text { ro-vo). Falta todo el apartado anterior }\end{array}$ \\
\hline \multirow[t]{4}{*}{$\begin{array}{l}\text { Unción del enfermo, recomendación del alma y } \\
\text { comunión (Quomodo inungantur infirmi) (f. } 146 \mathrm{r}^{\circ} \text { - } \\
148 \mathrm{r}^{\circ} \text { ) }\end{array}$} & $\begin{array}{l}\text { Unción del enfermo, recomendación del alma y comunión } \\
\text { (Qvando infirmus morti penitus apropinquauerit, percuciatur } \\
\text { tabula crebris ictibus; quo audito, omnes fratres relictis omnibus } \\
\text { que in manibus habuerint, accurrant uelociter ad morientem } \\
\text { dicentes: Credo in unum Deum. Repetentes illud bis uel ter, si } \\
\text { necesse fuerit. Si autem adhuc superuixerit, dicatur letania ista) } \\
\text { (f. 93ro-95ro) }\end{array}$ \\
\hline & 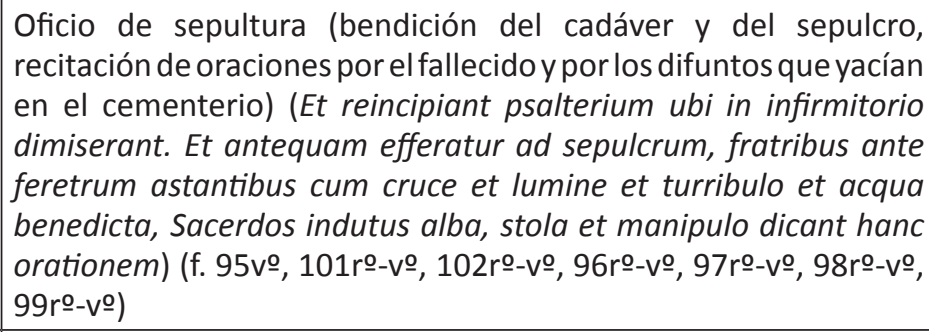 \\
\hline & $\begin{array}{l}\text { Rezo de los siete salmos penitenciales (Postea dicantur. VII. } \\
\text { specialis psalmi a fratribus in oratorio prostratis) (f. 99vo-100ro) }\end{array}$ \\
\hline & $\begin{array}{l}\text { Resumen ascético de vida cristiana (Que sunt instrumenta } \\
\text { bonorum operum) (f. 100ro-100vㅇ) }\end{array}$ \\
\hline
\end{tabular}




\section{BIBLIOGRAFÍA}

Alexandre-Bidon, D. 1998. La Mort au Moyer Age (XIIIXVIe siècle). Paris: Hachette.

Adeva Martín, A. 1992. "Cómo se preparaban para la muerte los españoles a finales del siglo XV". Anuario de Historia de la Iglesia 1: 113-138.

Adeva Martín, A. 2002. "Ars bene moriendi. La muerte amiga", en J. Aurell y J. Pavón (eds.), Ante la muerte. Actitudes, espacios y formas en la España medieval: 295360. Pamplona: Eunsa.

Avril, J. 1986. "La paroisse médiévale et la priere pour les morts", en J.-L. Lemaitre (coord.), L'Église et la mémoire des morts dans la France médiévale. Communications présentées à la table Ronde du C.N.R.S. le 14 juin 1982: 53-68. Paris: Études Augustinennes.

Baldó Alcoz, J., García de la Borbolla, A. y Pavón Benito, J. 2005. "Registrar la muerte (1381-1512). Un análisis de testamentos y mandas pías contenidos en los Protocolos Notariales Navarros". Hispania LXV/1:155-226.

Baldó Alcoz, J. 2005. Requiem aeternam. Ritos, actitudes y espacios en torno a la muerte en la Navarra bajomendieval (1234-1512). Pamplona: tesis doctoral inédita.

Baldó Alcoz, J. 2006. "Segunt a mi estado fazer pertenesce. Imagen y memoria de los grupos sociales privilegiados en la Navarra bajomedieval: el cortejo funerario", en VI Congreso de Historia de Navarra, 19-22 de Septiembre de 2006. Pamplona. Navarra: Memoria e Imagen II: 385-402, Pamplona: Sociedad de Estudios Históricos de Navarra (SEHN).

Baldó Alcoz, J. 2013. "Ceremonias y espacios funerarios", en J. Pavón Benito, J. Baldó Alcoz, A. García de la Borbolla, Pamplona y la muerte en el medievo: 67-127. Murcia: Sociedad Española de Estudios Medievales.

Baldó Alcoz, J. 2014. "La tradición cristiana del culto a los difuntos: sufragios, misas e indulgencias", en XXIV Semana de Estudios Medievales. Ubi sunt qui ante nos in hoc mundo fuere? De la tierra al cielo: 141-187. Nájera: Instituto de Estudios Riojanos.

Bastos, M. do R. 1996. "Prescrições sinodais sobre o culto dos mortos nos séculos XIII a XVI", en J. Mattoso (dir.), O Reino dos mortos na Idade Média peninsular: 109-124 Lisboa: Edições João Sá da Costa.

Hipona, A. de. 1995. "La piedad con los difuntos", en T. C. Martín (versión, introducción y notas), Obras completas de San Agustín. XL. Escritos varios (2): 415-475. Madrid: Biblioteca de Autores Cristianos.

Dettori, H. 1960. L'Officio dei Defuncti: storia, dissertazione storica-linguistica. Roma: P. Università Lateranense.

Devailly, G. 1981. "La liturgie de la préparation à la mor tau IX siècle". Bulletin et mémories de la societé archéologique du départament d'Ille-et-Villaine 83: 9-17.

Guiance, A. 1998. Los discursos sobre la muerte en la Castilla medieval (siglos VII-XV). Valladolid: Junta de Castilla y León. Consejería de Cultura.
Lauwers, M. 1997. La Mémoire des ancêtres le souci des morts. Morts, rites et société au Moyer Âge. Paris: Beauchesne.

Leclercq, J. 1942. "Un ancien recueil de leçons pour les vigiles des défunts". Révue bénédictine 58: 16-40.

Llopis Sarrió, J. 1964. "La Sagrada Escritura. Fuente de inspiración de la liturgia de difuntos del antiguo rito hispánico". Hispania Sacra 17: 349-391.

Martimort, A. G., 1983. L'Église en prière: Introduction à la liturgie. Paris: Desclée.

Martinena, J.J. 1997. Guía del Archivo General de Navarra. Pamplona: Gobierno de Navarra.

Mattoso, J. (dir.) 1996. O Reino dos mortos na Idade Média peninsular: Lisboa: Edições João Sá da Costa.

Mattoso, J. 1996. "Os rituais da morte na liturgia hispânica (séculos IV a IX)", en J. Mattoso (dir.), O Reino dos mortos na Idade Média peninsular: 55-74. Lisboa: Edições João Sá da Costa.

Mattoso, J. 1996. "O culto dos mortos no fim do século XI", en J. Mattoso (dir.), O Reino dos mortos na Idade Média peninsular: 75-85. Lisboa: Edições João Sá da Costa.

Ottosen, K. 1993. The Responsories and Versicles of the Latin Office of the Dead. Aarhus: Aarhus Universitet Press.

Pavón Benito, J. 2014. "La última escritura. La aparición y el desarrollo de la práctica testamental", en XXIV Semana de Estudios medievales. Ubi sunt qui ante nos in hoc mundo fuere? De la tierra al cielo: 217-237. Nájera: Instituto de Estudios Riojanos.

Pavón Benito, J. y García de la Borbolla, A. 2007. Morir en la Edad Media. La muerte en la Navarra medieval. Valencia: Universidad de Valencia.

Pavón Benito, J., Baldó Alcoz, J. y García de la Borbolla, A. 2013. Pamplona y la muerte en el medievo. Murcia: Sociedad Española de Estudios Medievales.

Paxton, F. S. 1990. Christianizing Death: The Creation of a Ritual Process in Early Medieval Europe. Ithaca and London: Cornell University Press.

Paxton, F. S. 2013. The Death ritual at Cluny in the Central Middle Ages. Le rituel de la mort à Cluny au Moyen Âge central, Turnhout: Brepols.

Righetti, M. 1955. Historia de la Liturgia. I. Introducción General. El año litúrgico. El breviario, C. Urtasun Irisarri (edic. española). Madrid: Editorial Católica.

Righetti, M. 1956. Historia de la Liturgia. II. La Eucaristía. Los sacramentos. Los sacramentales. Índices, C. Urtasun Irisarri (edic. española). Madrid: Editorial Católica.

Rutherford, R. 1980. The Death of a Christian: The rite of funerals. New York: Pueblo Pub. Co.

Sicard, D. 1978. La liturgie de la mort dans l'église latine des origins à la réforme carolingienne. Münster Westfalen: Aschendorff. 


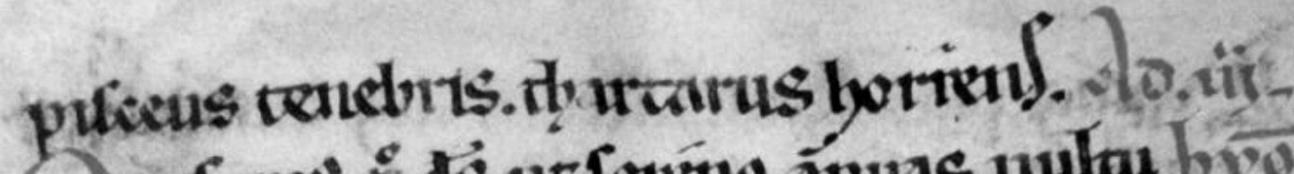

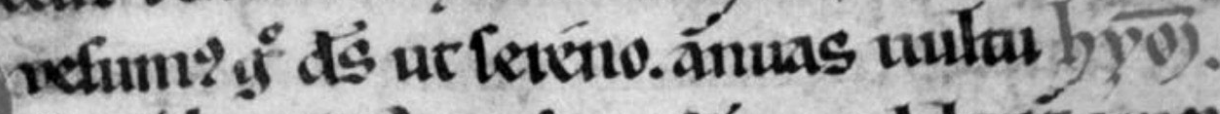

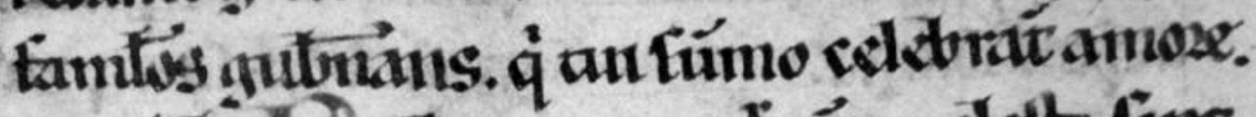

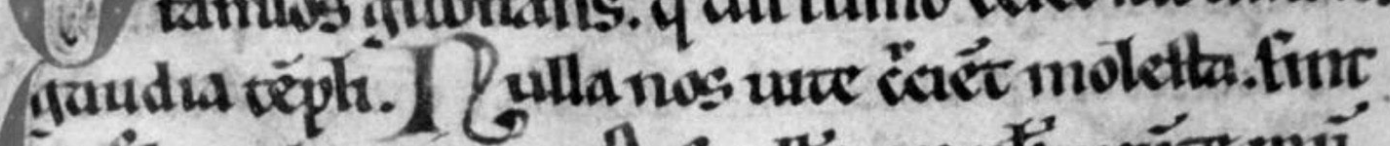

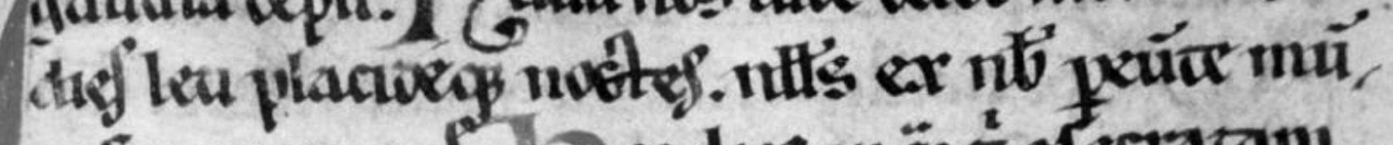

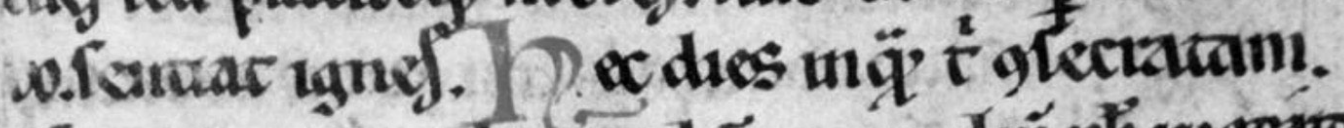

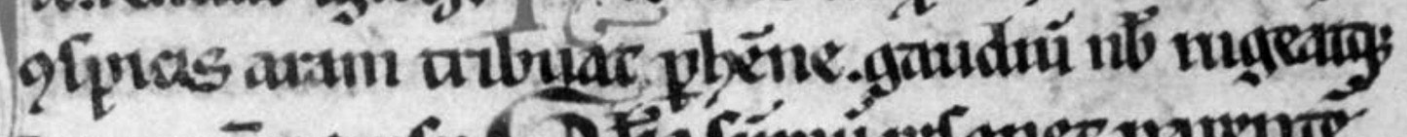

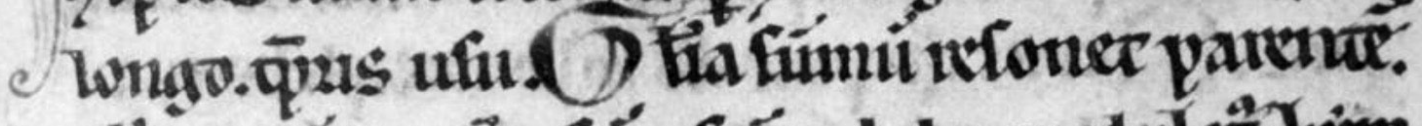

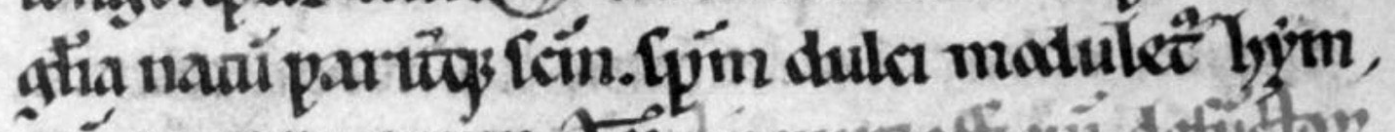

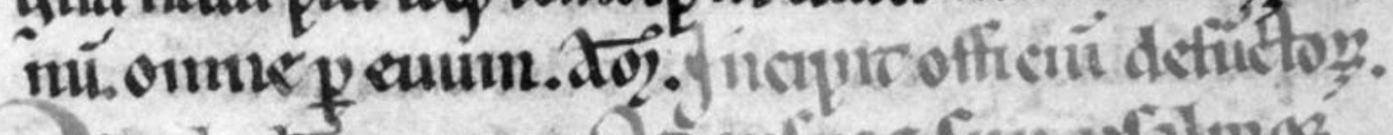

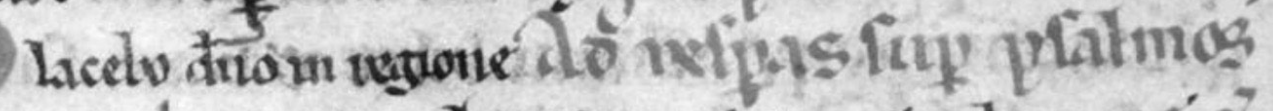

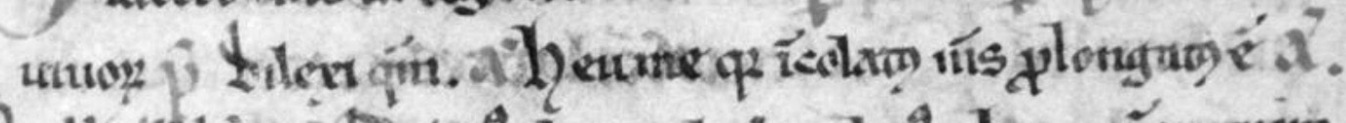

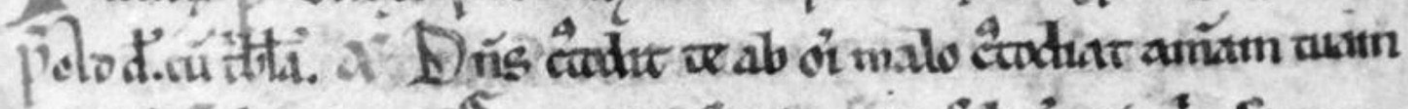

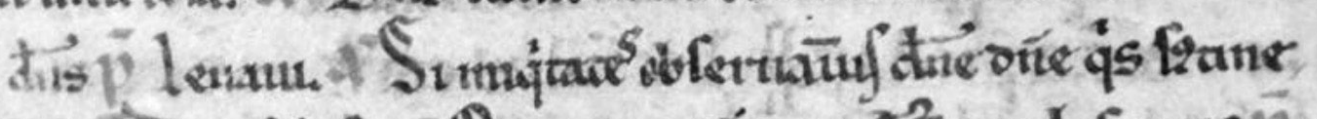

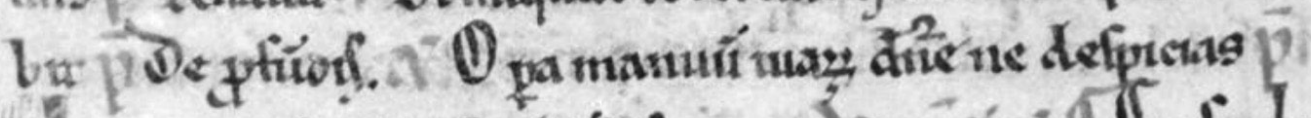

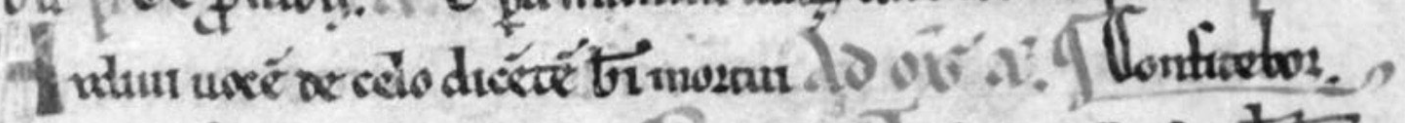

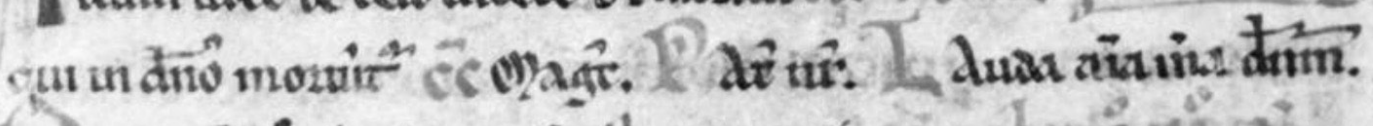

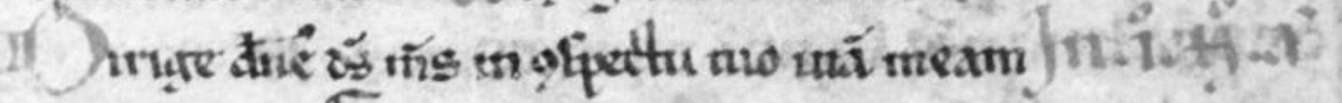

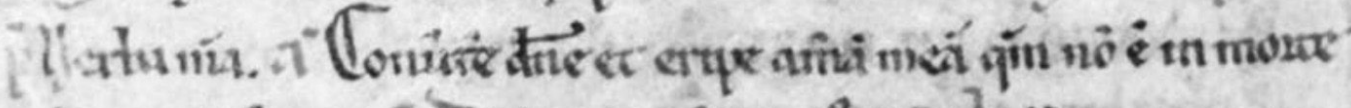

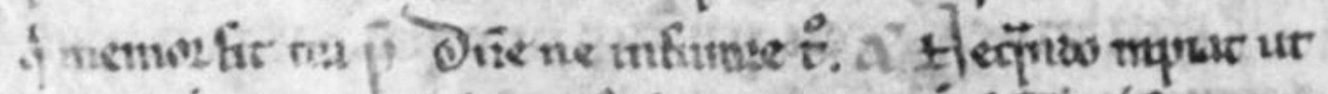

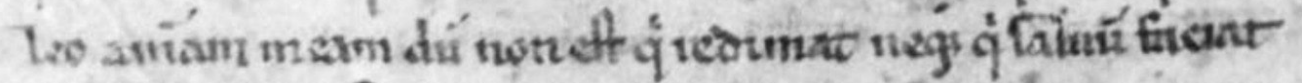

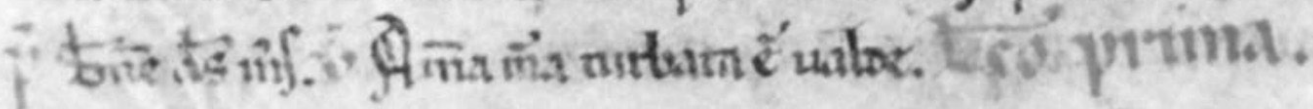


IMAGEN 2 Qumos an firm? 1mon pent

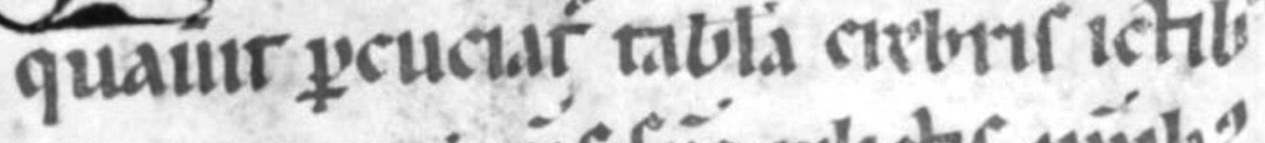

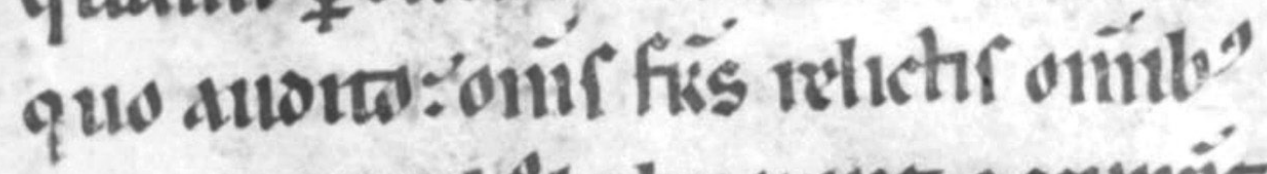

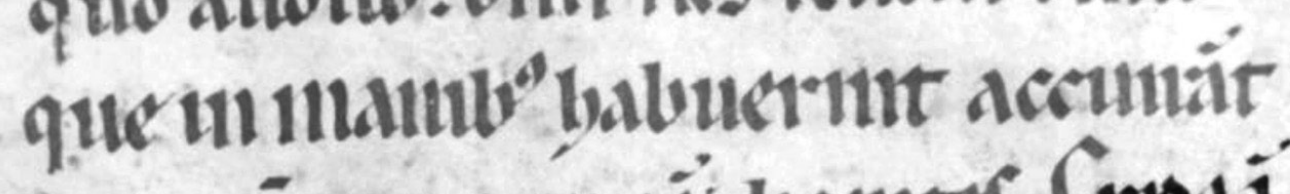

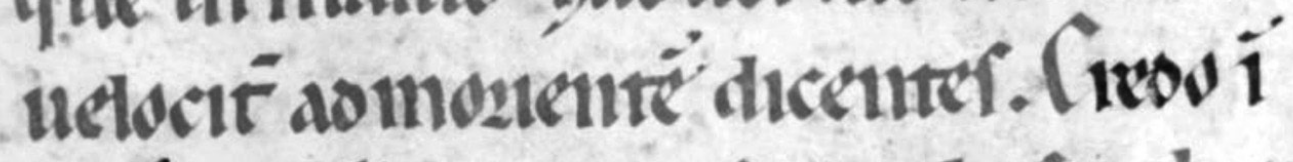
wui din. Reprentef illus bif uel tet finceste futert. S1 aut ashue fin uiverte decture letanta iftat

7) 4 ivts

(1) 1 ipes

16

pie alloullus

Paédeceldsóner.

fill troçutor numin.

deds.ail. el.

Spisfécds an.

Sētuntar aindsia).

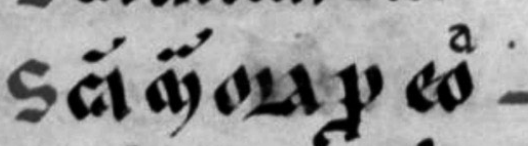

scid digeinty. - ब2.
Säi ingo ùguil a.丷.

scimilad-on.

sirgabribel-on.

Scerulbad-o\%.

0 sfó angli tat

chandivantyso.

0 selive fint a.

diner dite $y$ eo

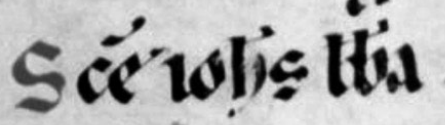

$\sqrt{2}$

desce patratrlo

Qvando infirmus morti penitus apropinquauerit

(AGN, Sección Códices y Cartularios, K. Códices Litúrgicos, 10.Libro de Oraciones (siglo XV), f. 93ro) 